\title{
Multiswitching Synchronization of Non-Identical Hyperchaotic Lorenz and Chen Systems
}

\author{
Laoye J. A. ${ }^{1}$, Ogundipe, S. O. ${ }^{2}$, Olonade, K O. ${ }^{3}$, Odunaike R. K. ${ }^{4}$ \\ ${ }^{1,2,3,4}$ Department of Physics, Olabisi Onabanjo University, Ago-Iwoye, Ogun State, Nigeria \\ ${ }^{2}$ Department of Physics, Federal College of Education, Abeokuta, Ogun State, Nigeria
}

${ }^{3}$ School of Science and Technology, Moshood Abiola Polytechnic, Abeokuta, Ogun State, Nigeria

\begin{abstract}
In this paper, synchronization of four-dimensional hyperchaotic Lorenz system, (drive system) with the Chen's system (response system) are investigated based on backstepping technique. Unlike the well-known $i=j$, multiswitching of the indices was employed in the usual master-slave synchronization scheme. We provided varieties of non-identical indices, that is, $i=j$ of the driver system. In this high dimension, more switching options for construct-ing the error space vector due to the large number of variables are available; and by implication providing variety of synchronizaion directions between variables of the master and the slave systems, which could be used in securing electronic information and communication.
\end{abstract}

Keywords: multiswitching, synchronization, hyperchaotic systems

\section{Introduction}

It is generally known that nonlinear deterministic dynamical systems are ubiquitous in nature and that they are well known for their unusual property of sensitive dependence on initial conditions which gives rise to their temporal complexity and apparent randomness. This property indeed leads to several intriguing attributes that have been investigated for many decades in the fields of sciences, medicine and engineering [1] as well as the study of nonlinear systems in mathematics [2]. In particular, chaotic dynamics, bifurcation structures, multistability of attractors, pattern formations, synchronization dynamics and many more have been rigorously investigated in attempts to elucidate and describe nonlinear behaviours and their potential applications.

One of the most important attributes of nonlinear dynamical systems is synchronization, originally proposed by Pecora and Carroll [3]. This concept has been considered as a major breakthrough in chaotic dynamics [4], due to its potential applications in modelling brain activities, chemical reactions; and more importantly, in information processing and secure communication [5]. These foreseen applications has triggered the enormous research attention given to chaos synchronization for over two decades. Increasing interest in the study of synchronization of chaotic systems has led to the discovery of various methods and types of synchronization.

In classifying chaos synchronization, we specifically mention here the original notion of identical/complete synchronization [3,6], general chaos synchronization [7], phase synchronization [8], lag synchronization [9], generalized synchronization $[10,11]$, measure synchronization [12-14], projective synchronization [1517], anticipated synchronization [18, 19], reduced-order synchronization [20], finite-time synchronization [21], and function projective synchronization [22].
A good number of previous works on chaos synchronization were aimed at achieving synchronization between state variables of the master systems and that of similar slave system. Notably, these conditions would undoubtedly constrain the synchronization to simultaneously take place in predictable and predetermined directions. In 2008, Ucar et al. [23] proposed the multiswitching synchronization of chaotic systems, in which the slave system's state variables synchronizes with different state variables of the driver. Despite its clear relevance to information security, only a few studies have been dedicated to this kind of synchronization to-date [4] [24] - [29].

In addition, most multiswitching synchronization scheme have been devoted to lower dimensional chaotic systems (See [4] and references therein). A few have considered hyperchaotic systems which indeed show complex nonperiodic behavior with at least two Lyapunov exponents (See Ref. [29] and references therein). However, it has been shown that secure communications based on low dimensional system does not guarantee absolute security due to the possibility of reconstructing the temporal complexity and apparent randomness; and thereby separating the signals from the secure information [6]. For this reason, the primary motivation of synchronization in secure communication which is to hide certain information to be transmitted in chaotic signal and retrieving by the technique of chaotic synchronization; maybe defeated by using low dimensional chaotic systems.

Motivated by the aforementioned, we examine in this paper, the multiswitching synchronization of a four- dimensional (4D) hyperchaotic Lorenz and Chen systems - a higher dimensional hyperchaotic system with at least two positive Lyapunov exponent and having the advantages of more switching options for constructing the error space vector due to the large number of available variables and more temporal complexity, with enriched dynamics providing varieties of synchronization directions between variables of the master and that of the slave systems. With such a 


\section{International Journal of Science and Research (IJSR) \\ ISSN (Online): 2319-7064}

Index Copernicus Value (2013): 6.14 | Impact Factor (2015): 6.391

scheme, it is hoped that improved security would be achieved when applied in communication.

The rest of the paper is organized as follows: in section 2, we give a brief description of the 4D hyperchaotic Lorenz and Chen systems. Section 3, general definitions and formulations of concepts. We designed the controllers based on backstepping section 4 . In section 5 we gave numerical simulation results and the paper is concluded in section 6 .

\section{System Description}

\subsection{Description of the Hyperchaotic Lorenz's model}

Based on the Lorenz system, a new chaotic system was reported by [31] which has attracted the attention of many researchers [32-35]. The Lorenz chaotic system is described by

$$
\begin{aligned}
& \dot{x}=a(y-x) \\
& \dot{y}=c x-x z \\
& \dot{z}=x y-b z
\end{aligned}
$$

where $\mathrm{a}, \mathrm{b}$ and $\mathrm{c}$ are positive real constants. It is a $3 \mathrm{D}$ autonomous system with six terms including only two quadratic terms in a form very similar to the Chen and $\mathrm{Lu}$ systems in [36-39], but it has three very different fixed points: one saddle and two stable node-foci. By introducing a linear feedback controller to the second equation of the Lorenz like system (1), the following new hyperchaotic system is obtained [40]:

$$
\begin{aligned}
& \dot{x}=a(y-x) \\
& \dot{y}=c x+y-x z-w \\
& \dot{z}=x y-b z \\
& \dot{w}=d y z
\end{aligned}
$$

For the purpose of this work, we let $a=a_{1}=10$, $b=b_{1}=8 / 3, c=c_{1}=28, d_{1}=0.1$. The attractors of the system at the states $x^{-}-\mathrm{y}, \mathrm{x}-\mathrm{z}, \mathrm{x}-\mathrm{w}, \mathrm{y}-\mathrm{z}, \mathrm{y}-\mathrm{w}, \mathrm{z}-\mathrm{x}, \mathrm{z}^{-} \mathrm{y}$ and $z^{-}-w$ are as shown in the upper part of Figure 1 while the time series of the combined state of the system is as shown in the lower part.

\subsection{Description of the Hyperchaotic Chen's model}

The hyperchaotic Chen system is given by

$$
\begin{aligned}
& \dot{x}=a(y-x)+w \\
& \dot{y}=d x-x z+c y \\
& \dot{z}=x y-b z \\
& \dot{w}=y z+e w
\end{aligned}
$$

Where $\mathrm{a}=\mathrm{a}_{2}=35, \mathrm{~b}=\mathrm{b}_{2}=3, \mathrm{c}=\mathrm{c}_{2}=12, \mathrm{~d}=\mathrm{d}_{2}=7, \mathrm{e}=0.5$ are parameters. The attractors of the system at the states $\mathrm{x}-\mathrm{y}, \mathrm{x}-\mathrm{z}, \mathrm{x}-\mathrm{w}, \mathrm{y}-\mathrm{z}, \mathrm{y}-\mathrm{w}, \mathrm{z}-\mathrm{x}, \mathrm{z}-\mathrm{y}$ and $\mathrm{z}^{-} \mathrm{w}$ are as shown in the upper part while the time series is shown in the lower part of Figure 2.

\section{Definition and Formulation of 4. Design of Controllers}

Let us consider the following master-slave $\mathrm{n}$ dimensional chaotic systems, where the master systems is given by

$$
\begin{aligned}
& \dot{x}_{1}=f_{1}\left(x_{1}\right) \\
& \dot{x}_{2}=f_{2}\left(x_{2}\right) \\
& \dot{x}_{m}=f_{m}\left(x_{m}\right)
\end{aligned}
$$

and the controlled slave system is given by

$$
\begin{aligned}
& \dot{y}_{1}=g_{1}\left(y_{1}\right) \\
& \dot{y}_{2}=g_{2}\left(y_{2}\right) \\
& \dot{y}_{n}=g_{n}\left(y_{n}\right)
\end{aligned}
$$

where $x_{1}, y_{1}(i=1,2 \ldots n) \quad \varepsilon \mathrm{R}^{\mathrm{n}}$ are state space vectors of the systems, fn and $g_{n}: R^{n} \rightarrow R^{n}$ are two continuous vector functions and $\mathrm{u}_{\mathrm{i}}(\mathrm{i}=1,2, \ldots \mathrm{n}): \mathrm{R}^{\mathrm{n}} \rightarrow \mathrm{R}^{\mathrm{n}}$ is a nonlinear control function.

\section{Definition 1}

According to [41] in [4], If there exists two constants matrices $\mathrm{A}, \mathrm{B} \varepsilon \mathrm{R}^{\mathrm{n}}$ and $\mathrm{A}, \mathrm{B}=0$, such that $\lim \infty \mathrm{kByi}-$ Axik $=0$ and where k.k is the matrix norm and A,B are scaling matrices, then systems (4) and (5) are said to be in synchronization.

\section{Comment 1}

The error states in relation to the definition 1 are strictly chosen to satisfy the definition $\mathrm{e}_{\mathrm{ij}}(\mathrm{i}=\mathrm{j}=1,2,3 \ldots \mathrm{n})$ are the indices of the error and $\mathrm{n}$ refers to the number of dimension of the chaotic system. Hence, we can write $e_{i j}=y_{i}-x_{j}$ where $\mathrm{y}_{\mathrm{i}}, \mathrm{x}_{\mathrm{i}}$ are the slave and master systems respectively. We observe that for $e_{i j}=y_{i}-x_{j}(i=j=1,2,3 \ldots n)$, we have $e_{11}=y_{1}$ $\mathrm{x}_{1}, \quad \mathrm{e}_{22}=\mathrm{y}_{2}-\mathrm{x}_{2}, \quad \mathrm{e}_{33}=\mathrm{y}_{3}-\mathrm{x}_{3}, \ldots \mathrm{e}_{\mathrm{nn}}=\mathrm{y}_{\mathrm{n}}-\mathrm{x}_{\mathrm{n}}$ and this is called complete synchronization, in this case there is no switching.

If the error states in relation to definition 1 are redefined such that $e_{i j}(i=j)$ or $e_{i j}(i=j)$ and any of the member in the error dynamical system is interchanged and $\lim \infty$ $\mathrm{kBy}_{\mathrm{i}}-\mathrm{Axik}=0$ then, systems (4) and (5) are said to be in switched synchronization state.

\section{Comment 2}

If $\mathrm{i}$ and $\mathrm{j}$ are chosen such that for $\mathrm{e}_{\mathrm{ij}}=\mathrm{y}_{\mathrm{i}}-\mathrm{x}_{\mathrm{j}},(\mathrm{i}=\mathrm{j})$, then we have

$$
\begin{aligned}
& \mathrm{e}_{11}=\mathrm{y}_{1}-\mathrm{x}_{1}, \mathrm{e}_{12}=\mathrm{y}_{1}-\mathrm{x}_{2}, \mathrm{e}_{13}=\mathrm{y}_{1}-\mathrm{x}_{3}, \mathrm{e}_{14}=\mathrm{y}_{1}-\mathrm{x}_{4} \ldots \mathrm{e}_{1 \mathrm{n}}=\mathrm{y}_{1}-\mathrm{x}_{\mathrm{n}}, \\
& \mathrm{e}_{21}=\mathrm{y}_{2}-\mathrm{x}_{1}, \mathrm{e}_{22}=\mathrm{y}_{2}-\mathrm{x}_{2}, \mathrm{e}_{23}=\mathrm{y}_{2}-\mathrm{x}_{3}, \mathrm{e}_{24}=\mathrm{y}_{2}-\mathrm{x}_{4} \ldots \mathrm{e}_{2 \mathrm{n}}=\mathrm{y}_{2}-\mathrm{x}_{\mathrm{n}}, \\
& \mathrm{e}_{31}=\mathrm{y}_{3}-\mathrm{x}_{1}, \mathrm{e}_{32}=\mathrm{y}_{3}-\mathrm{x}_{2}, \mathrm{e}_{33}=\mathrm{y}_{3}-\mathrm{x}_{3}, \mathrm{e}_{34}=\mathrm{y}_{3}-\mathrm{x}_{4} \ldots \mathrm{e}_{3 \mathrm{n}}=\mathrm{y}_{3}-\mathrm{x}_{\mathrm{n}}, \\
& \mathrm{e}_{41}=\mathrm{y}_{4}-\mathrm{x}_{1}, \mathrm{e}_{42}=\mathrm{y}_{4}-\mathrm{x}_{2}, \mathrm{e}_{43}=\mathrm{y}_{4}-\mathrm{x}_{3}, \mathrm{e}_{44}=\mathrm{y}_{4}-\mathrm{x}_{4} \ldots \mathrm{e}_{4 \mathrm{n}}=\mathrm{y}_{4}-\mathrm{x}_{\mathrm{n},}, \\
& \mathrm{e}_{\mathrm{m} 1}=\mathrm{y}_{\mathrm{m}}-\mathrm{x}_{1}, \mathrm{e}_{\mathrm{m} 2}=\mathrm{y}_{\mathrm{m}}-\mathrm{x}_{2}, \mathrm{e}_{\mathrm{m} 3}=\mathrm{y}_{\mathrm{m}}-\mathrm{x}_{3}, \ldots \mathrm{e}_{\mathrm{mn}}=\mathrm{y}_{\mathrm{m}}-\mathrm{x}_{\mathrm{n}}
\end{aligned}
$$

for $\mathrm{m}$ dimensions of the slave systems and $\mathrm{n}$ dimensions of the master systems. We comment here also that there are various switchings that can be formulated in addition to the above.

From system (4), we let $\mathrm{x}=\mathrm{x}_{1}, \mathrm{y}=\mathrm{y}_{1}, \mathrm{z}=\mathrm{z}_{1}$ and $\mathrm{w}=\mathrm{w}_{1}$ for the master system and $\mathrm{x}=\mathrm{x}_{2}, \mathrm{y}=\mathrm{y}_{2}, \mathrm{y}=\mathrm{z}_{2}$ and $\mathrm{w}=\mathrm{w}_{2}$ for the slave system, and we chose the following switchings 


\section{International Journal of Science and Research (IJSR) \\ ISSN (Online): 2319-7064}

Index Copernicus Value (2013): 6.14 | Impact Factor (2015): 6.391

Let the master system be

$$
\begin{aligned}
& \mathrm{x}=\mathrm{a}_{1}\left(\mathrm{y}_{\mathrm{t}}-\mathrm{x}_{\mathrm{t}}\right) \\
& \dot{\mathrm{y}}_{\mathrm{l}}=\mathrm{c}_{\mathrm{i}} \mathrm{x}_{1}+\mathrm{y}_{1}-\mathrm{x}_{1} \mathrm{z}_{1}-\mathrm{w}_{1} \\
& \dot{\mathrm{z}}_{\mathrm{l}}=\mathrm{x}_{\mathrm{t}} \mathrm{y}_{\mathrm{t}}-\mathrm{b}_{\mathrm{i}} \mathrm{z}_{\mathrm{i}} \\
& \mathrm{w}=\mathrm{d}_{\mathrm{i}} \mathrm{y}_{1} \mathrm{z} \text { : }
\end{aligned}
$$

and the slave system as

$$
\begin{aligned}
& \dot{\mathrm{x}}_{2}=\mathrm{a}_{2}\left(\mathrm{y}_{2}-\mathrm{x}_{2}+\mathrm{w}_{2}\right)+\mathrm{u}_{1} \\
& \dot{\mathrm{y}}_{2}=\mathrm{d}_{2} \mathrm{x}_{2}-\mathrm{x}_{2} \mathrm{z}_{2}+\mathrm{c}_{2} \mathrm{y}_{2}+\mathrm{u}_{2} \\
& \dot{\mathrm{z}}_{2}=\mathrm{x}_{2} \mathrm{y}_{2}-\mathrm{b}_{2} \mathrm{z}_{2}+\mathrm{u}_{3} \\
& \dot{\mathrm{w}}_{2}=\mathrm{y}_{2} \mathrm{z}_{2}+\mathrm{ew}_{2}+\mathrm{u}_{4}
\end{aligned}
$$

be the slave system, where $\mathrm{u}_{1}, \mathrm{u}_{2}, \mathrm{u}_{3}$ and $\mathrm{u}_{4}$ are the set of nonlinear controllers. The switches are chosen as:

Case 1: $\dot{e}_{13}=\mathrm{x}_{2}-\mathrm{z}_{1}, \dot{e}_{22}=\mathrm{y}_{2}-\mathrm{y}_{1}, \dot{e}_{34}=\mathrm{z}_{2}-\mathrm{w}_{1}, \dot{e}_{41}=\mathrm{w}_{2}-\mathrm{x}_{1}$, Case 2: $\dot{e}_{12}=\mathrm{x}_{2}-\mathrm{y}_{1}, \dot{e}_{23}=\mathrm{y}_{2}-\mathrm{z}_{1}, \dot{e}_{34}=\mathrm{z}_{2}-\mathrm{w}_{1}, \dot{e}_{41}=\mathrm{w}_{2}-\mathrm{x}_{1}$, Case 3: $\dot{e}_{14}=\mathrm{x}_{2}-\mathrm{w}_{1}, \dot{e}_{23}=\mathrm{y}_{2}-\mathrm{z}_{1}, \dot{e}_{31}=\mathrm{z}_{2}-\mathrm{x}_{1}, \dot{e}_{42}=\mathrm{w}_{2}-\mathrm{y}_{1}$, Case 4: $\dot{e}_{11}=\mathrm{x}_{2}-\mathrm{x}_{1}, \dot{e}_{21}=\mathrm{y}_{2}-\mathrm{x}_{1}, \dot{e}_{33}=\mathrm{z}_{2}-\mathrm{z}_{1}, \dot{e}_{44}=\mathrm{w}_{2}-\mathrm{w}_{1}$, Case 5: $\dot{e}_{14}=\mathrm{x}_{2}-\mathrm{w}_{1}, \dot{e}_{21}=\mathrm{y}_{2}-\mathrm{x}_{1}, \dot{e}_{34}=\mathrm{z}_{2}-\mathrm{w}_{1}, \dot{e}_{43}=\mathrm{w}_{2}-\mathrm{z}_{1}$.

Case 1

Using the notations in comment 2 and differentiating the error dynamics, we have

$$
\begin{aligned}
& \dot{e}_{13}=\dot{x}_{2}-\dot{z}_{1} \\
& \dot{e}_{22}=\dot{y}_{2}-\dot{y}_{1} \\
& \dot{e}_{34}=\dot{z}_{2}-\dot{w}_{1} \\
& \dot{e}_{41}=\dot{w}_{2}-\dot{x}_{1}
\end{aligned}
$$

and by substituting

$$
\begin{aligned}
& \dot{e}_{13}=-\mathrm{a}_{2} \mathrm{e}_{13}+\mathrm{a}_{2} \mathrm{e}_{2}+ \mathrm{a}_{2}\left(\mathrm{y}_{1}-\mathrm{z}_{1}\right)-\mathrm{x}_{1} \mathrm{y}_{1}+\mathrm{bz}_{1}+\mathrm{w}_{2}+\mathrm{u}_{1} \\
& \dot{\eta}_{1}=-\left(\mathrm{a}_{2}-\mathrm{k}\right) \eta_{1}+\mathrm{a}_{2} \mathrm{\eta}_{2} \\
& \dot{e}_{22}=2 \mathrm{c}_{2} \mathrm{e}_{22}+\mathrm{e}_{13} \mathrm{~d}_{2}-\mathrm{z}_{2}\left(\mathrm{e}_{13}+\mathrm{z}_{1}\right)+\mathrm{y}_{1}\left(\mathrm{c}_{2}-1\right)+\mathrm{z}_{1}\left(\mathrm{~d}_{2}+\mathrm{x}_{1}\right)-\mathrm{c}_{1} \mathrm{x}_{1}+\mathrm{w}_{1}-\mathrm{c}_{2} \mathrm{e}_{22}+\mathrm{u}_{2}(15)
\end{aligned}
$$

We stabilize (15) by describing the second Lyapunov function as

$v_{2}=v_{1}+\frac{1}{2} \eta_{2}$ $\dot{e}_{22}=2 \mathrm{c}_{2} \mathrm{e}_{22}+\mathrm{e}_{13} \mathrm{~d}_{2}-\mathrm{z}_{2}\left(\mathrm{e}_{13}+\mathrm{z}_{1}\right)+\mathrm{y}_{1}\left(\mathrm{c}_{2}-1\right)+\mathrm{z}_{1}\left(\mathrm{~d}_{2}+\mathrm{x}_{1}\right)-\mathrm{c}_{1} \mathrm{x}_{1}$

$+\mathrm{w}_{1}-\mathrm{c}_{2} \mathrm{e}_{22}+\mathrm{u}_{2}$

$\dot{e}_{34}=-\mathrm{b}_{2} \mathrm{e}_{34}-\mathrm{e}_{22}+\mathrm{e}_{22}\left(\mathrm{x}_{2}+1\right)+\mathrm{x}_{2} \mathrm{y}_{1}-\mathrm{b}_{2} \mathrm{w}_{1}-\mathrm{d}_{1} \mathrm{y}_{1} \mathrm{z}_{1}+\mathrm{u}_{3}$

$\dot{e}_{41}=-\mathrm{ee}_{41}+2 \mathrm{ee}_{41}-\mathrm{e}_{34}+\mathrm{e}_{34}\left(\mathrm{y}_{2}+1\right)+\mathrm{y}_{2} \mathrm{w}_{1}+\mathrm{x}_{1}\left(\mathrm{e}+\mathrm{a}_{1}\right)-$ $\mathrm{a}_{1} \mathrm{y}_{1}+\mathrm{u}_{4}$

With error dynamics presented above, if appropriate $\mathrm{u}_{1}, \mathrm{u}_{2}$, $\mathrm{u}_{3}$ and $\mathrm{u}_{4}$ are chosen such that the system is stable and unchanged, then asymptotic stabilization would be realized leading to synchronization of the system. If $\mathrm{e}_{13}=\eta_{1}$, its time derivative is $\dot{\eta}_{1}=\dot{e}_{13}$ and we can stabilize the first part of (9), using the Lyapunov function, as

$$
v_{1}=\frac{1}{2} \eta_{1}^{2}
$$

whose time derivative is

$$
\dot{v}_{1}=\eta_{1} \dot{\eta}_{1}
$$

By substituting for $\eta_{1}{ }_{1}$ from (9) we have

$$
\dot{\mathrm{v}}_{\mathrm{l}}=\eta_{1}\left(-\mathrm{a}_{2} \mathrm{e}_{13}+\mathrm{a}_{2} \mathrm{e}_{2}+\mathrm{a}_{2}\left(\mathrm{y}_{1}-\mathrm{z}_{1}\right)-\mathrm{x}_{1} \mathrm{y}_{1}+\mathrm{bz}_{1}+\mathrm{w}_{2}+\mathrm{u}_{1}\right)
$$

choosing $\mathrm{e}_{22}=\alpha_{1}\left(\eta_{2}\right)$ as a virtual controller, we have

$$
\mathrm{u}_{1}=-\mathrm{a}_{2}\left(\mathrm{y}_{1}-\mathrm{z}_{1}\right)+\mathrm{x}_{1} \mathrm{y}_{1}-\mathrm{bz}_{1}+\mathrm{km}_{1}
$$

So that

$$
\dot{\mathrm{v}}_{\mathrm{i}}=-\left(\mathrm{a}_{2}-\mathrm{k}\right) \eta^{2}
$$

which is $\leq 0$ for $\mathrm{a}_{2}>0, \mathrm{k} \leq 0$. Thus the subsystem is negative definite and assymptotically stable. Since the error between $\mathrm{e}_{22}$ and $\alpha_{1}\left(\mathrm{z}_{2}\right)$ is estimative as $\dot{\eta}_{2}=\mathrm{e}_{22}-\alpha_{1}\left(\eta_{2}\right)$ and $\alpha_{1}\left(\eta_{2}\right)=0$, we can write the $\left(\eta_{1}, \eta_{2}\right)$ subsystem as

whose time derivative is

$$
\mathrm{u}_{2}=-2 \mathrm{c}_{2} \mathrm{e}_{22}+\mathrm{z}_{2}\left(\mathrm{e}_{13}+\mathrm{z}_{1}\right)-\mathrm{y}_{1}\left(\mathrm{c}_{2}-1\right)-\mathrm{z}_{1}\left(\mathrm{~d}_{2}+\mathrm{x}_{1}\right)+\mathrm{c}_{1} \mathrm{x}_{1}-\mathrm{w}_{1}+\mathrm{kn}_{2}
$$

So that

$$
\dot{v}_{2}=-\left(a_{2}-k\right) \eta_{1}^{2}-\left(c_{2}-k\right) \eta_{2}^{2}
$$

which is $\leq 0$ for $\mathrm{a}_{2}>0, \mathrm{c}_{2}>0, \mathrm{k} \leq 0$. Thus the subsystem is negative definite and assymptotically stable. Since the error between $\mathrm{e}_{13}$ and $\alpha_{2}\left(\eta_{1}\right)$ is estimative as $\eta_{1}=\mathrm{e}_{13}-\alpha_{1}\left(\eta_{1}\right)$ and $\alpha_{2}\left(\eta_{1}\right)=0$, let $e_{34}$ be $\eta_{3}$, we can write the $\left(\eta_{1}, \eta_{2}, \eta_{3}\right)$ subsystem as

$\dot{\eta}_{1}=-\left(\mathrm{a}_{2}-\mathrm{k}\right) \eta_{1}+\mathrm{a}_{2} \eta_{2}$

$\dot{\eta}_{2}=-\left(c_{2}-\mathrm{k}\right) \eta_{2}+d_{2} \eta_{1}$

$\dot{\mathrm{r}}_{\mathrm{B}}=-\mathrm{b}_{2} \mathrm{e}_{34}-\mathrm{e}_{22}+\mathrm{e}_{22}\left(\mathrm{x}_{2}+1\right)+\mathrm{x}_{2} \mathrm{y}_{1}-\mathrm{b}_{2} \mathrm{w}_{1}-\mathrm{d}_{1} \mathrm{y}_{1} \mathrm{z}_{1}+\mathrm{u}_{3}$

We can stabilize (20) by defining the third Lyapunov function as

$$
\dot{v}_{2}=\dot{v}_{1}+\eta_{2} \dot{\eta}_{2}
$$

By substituting for $\dot{\eta}_{2}$ in the derivative of (16), and choosing $\mathrm{e}_{13}=\alpha_{2}\left(\eta_{1}\right)$ as a virtual controller, we can write 


\section{International Journal of Science and Research (IJSR)}

ISSN (Online): 2319-7064

Index Copernicus Value (2013): 6.14 | Impact Factor (2015): 6.391

$\dot{\eta}_{1}=-\left(\mathrm{a}_{2}-\mathrm{k}\right) \eta_{1}+\mathrm{a}_{2} \eta_{2}$

$\dot{\eta}_{2}=-\left(\mathrm{c}_{2}-\mathrm{k}\right) \eta_{2}+\mathrm{d}_{2} \eta_{1}$

$\dot{\eta}_{3}=-\left(b_{2}-k\right) \eta_{3}-\eta_{2}$

$\dot{\eta}_{4}=-e^{e} e_{41}+2 e_{41}-e_{34}+e_{34}\left(y_{2}+1\right)+y_{2} w_{1}+x_{1}\left(e+a_{1}\right)-a_{1} y_{1}+u_{4}$ function as

$$
v_{4}=v_{3}+\frac{1}{2} \eta_{4}^{2}
$$

whose time derivative is

$$
\dot{v}_{4}=\dot{v}_{3}+\eta_{4} \dot{\eta}_{4}
$$

We can stabilize (25) by defining the fourth Lyapunov

By choosing $\mathrm{e}_{34}=\alpha_{4}\left(\eta_{3}\right)$ as a virtual controller and choosing

We have

$$
\mathrm{u}_{4}=-2 \mathrm{ee}_{41}-\mathrm{e}_{34}+\mathrm{e}_{34}\left(\mathrm{y}_{2}+1\right)-\mathrm{y}_{2} \mathrm{w}_{1}-\mathrm{x}_{1}\left(\mathrm{e}+\mathrm{a}_{1}\right)+\mathrm{a}_{1} \mathrm{y}_{1}+\mathrm{k} \eta_{4}
$$

$$
\dot{v}_{4}=-\left(a_{2}-k\right) \eta_{1}^{2}-\left(c_{2}-k\right) \eta_{2}^{2}-\left(b_{2}-k\right) \eta_{3}^{2}-(e-k) \eta_{4}^{2}
$$

which is $\leq 0$ for $\mathrm{a}_{2}>0, \mathrm{~b}_{2}>0, \mathrm{c}_{2}>0$ and $\mathrm{k} \leq 0$ Thus, the whole system $\left(\eta_{1}, \eta_{2}, \eta_{3}, \eta_{4}\right)$ is assymptotically stable. For other cases (2-5), the controllers are as presented in equations (30), (31), (32) and (33) respectively.

$$
\begin{aligned}
& \mathrm{u}_{1}=-\mathrm{a}_{2}\left(\mathrm{z}_{1}-\mathrm{y}_{1}\right)+\mathrm{x}_{1} \mathrm{c}_{1}+\mathrm{y}_{1}-\mathrm{x}_{1} \mathrm{z}_{1}-\mathrm{w}_{1}-\mathrm{w}_{2}+\mathrm{k}_{1} \\
& \mathrm{u}_{2}=-\eta_{2}\left(\mathrm{c}_{2}+1\right)+\mathrm{z}_{2}\left(\mathrm{e}_{1}+\mathrm{y}_{1}\right)-\mathrm{z}_{1}\left(\mathrm{c}_{2}+\mathrm{b}_{1}\right)-\mathrm{d}_{2} \mathrm{y}_{2}+\mathrm{x}_{1} \mathrm{y}_{1}+\mathrm{k} \eta_{2} \\
& \mathrm{u}_{3}=-\eta_{1}\left(\mathrm{y}_{2}+1\right)-\mathrm{y}_{1} \mathrm{y}_{2}+\mathrm{y}_{1} \mathrm{~d}_{1} \mathrm{z}_{1}+\mathrm{b}_{2} \mathrm{w}_{1}+\mathrm{k} \eta_{3} \\
& \mathrm{u}_{4}=-\eta_{4}(\mathrm{e}+1)-\eta_{3}\left(\mathrm{y}_{2}+1\right)-\mathrm{y}_{2} \mathrm{w}_{1}-\mathrm{x}_{1}\left(\mathrm{e}+\mathrm{a}_{1}\right)+\mathrm{a}_{1} \mathrm{y}_{1}+\mathrm{k} \eta_{4} \\
& \mathrm{u}_{1}=-\mathrm{a}_{2}\left(\mathrm{z}_{1}-\mathrm{w}_{1}\right)-\mathrm{w}_{2}+\mathrm{d}_{1} \mathrm{y}_{1} \mathrm{z}_{1}+\mathrm{k} \eta_{1} \\
& \mathrm{u}_{2}=-\eta_{2}\left(\mathrm{c}_{2}+1\right)+\eta_{3}\left(\mathrm{x}_{2}+1\right)-\mathrm{x}_{2}\left(\mathrm{~d}_{2}-\mathrm{x}_{1}\right)-\mathrm{z}_{1}\left(\mathrm{c}_{2}+\mathrm{b}_{1}\right)+\mathrm{x}_{1} \mathrm{y}_{1}+\mathrm{k} \eta_{2} \\
& \mathrm{u}_{3}=-\eta_{2}\left(\mathrm{x}_{2}+1\right)-\mathrm{x}_{1}\left(\mathrm{a}_{1}-\mathrm{b}_{2}\right)-\mathrm{x}_{2} \mathrm{z}_{1}+\mathrm{a}_{1} \mathrm{y}_{1}+\mathrm{k} \eta_{3} \\
& \mathrm{u}_{4}=-\eta_{4}(\mathrm{e}+1)-\eta_{3}\left(\mathrm{y}_{2}+1\right)-\mathrm{x}_{1}\left(\mathrm{y}_{2}-\mathrm{c}_{1}+\mathrm{z}_{1}\right)-\mathrm{y}_{1}(\mathrm{e}-1)-\mathrm{w}_{1}+\mathrm{k} \eta_{4}
\end{aligned}
$$

\section{Numerical Simulations}

Here we present our numerical simulation in order to verify the effectiveness of controllers derived above and those in (30)-(33). We used the Runge-Kutta simulation tool. In all the figures presented, the hyperchaotic Lorenz system (drive) parameters selected remain constant at $\mathrm{a}_{1}=10, \mathrm{~b}_{1}=$ $8 / 3, c_{1}=28, d_{1}=2.25$, with initial condition values $x_{1}=0.1$, $\mathrm{y}_{1}=0.1, \mathrm{z}_{1}=0.1, \mathrm{w}_{1}=0.1$, the hyperchaotic Chen system (response), parameters selected remain constant at $\mathrm{a}_{2}=35$, $\mathrm{b}_{2}=3, \mathrm{c}_{2}=12, \mathrm{~d}_{2}=7, \mathrm{e}=0.5$ and variable parameters chosen as $\mathrm{x}_{2}=0.5, \mathrm{y}_{2}=0.01, \mathrm{z}_{2}=0.8, \mathrm{w}_{2}=0.5$. The step size was maintained at $\mathrm{H}=0.005$ and $\mathrm{t}=10$. The synchronization of the slave system with the master system at each of the state variable is presented in (Figures 3 ) for states $e_{1}, e_{2}, e_{3}$ and $e_{4}$ respectively, while the fifth graph in this figure shows the result for the combined states for case 1. In each of these figures, synchronization took place when each of the controllers $\mathrm{u}_{1}, \mathrm{u}_{2}, \mathrm{u}_{3}$ and $\mathrm{u}_{4}$ was activated at $\mathrm{t} \geq 10$. Using the same parameters, and making use of our results for other cases 2, 3, 4 and 5 for the non-identical hyperchaotic systems unified and periodically converged to zero as shown in the figures 4 as time tends to infinity which signifies that the global synchronization between systems (6) and (7) has been achieved.

\section{Conclusion}

Summarily in this paper, we have proposed, analysed and validated the possibility of the multiswitching synchronization of the non-identical hyperchaotic Lorenz (drive) and that of Chen's (response)systems based on integrator backstepping technique. We extended the usual master-slave synchronization scheme for low order chaotic systems to study the synchronization of this higher order systems on one side, and provided various switches in the 


\section{International Journal of Science and Research (IJSR) \\ ISSN (Online): 2319-7064 \\ Index Copernicus Value (2013): 6.14 | Impact Factor (2015): 6.391}

design of the controllers. Each of the 4-dynamical states was successfully synchronized. The synchronization of each of the switches in other cases were also successful. By implication, electronic information can be hidden in any or all of this 4D hyperchaotic system and such information can be locked up in any of the states in each of the cases. Such information can be transferred, communicated and retrieved by applying the control inputs for each or all the dynamical states and respective switches. This makes the information more secure not only because of the hyperchaos status of the system in consideration, but also the several switches that must be unlocked to retrieve the information. Our numerical results confirm the effectiveness of the analytical technique and we belief that they are observable in laboratory experiments.

\section{Acknowledgment}

Ogundipe, S. O. and Olonade, K.O. acknowledge research support from the Federal Government of Nigeria through the Tertiary Education Trust Fund (TETFUND).

\section{References}

[1] Strogatz, S.H. Nonlinear dynamics and chaos: with applications to physics, biology, chemistry and engineering, in: Nonlinear Dynamics and Chaos: with Applications to Physics, Biology, Chemistry and Engineering, (Persues Books Publishing, LLC, USA), 2000, pp. 1-20.

[2] Martynyuk, A.A., Khusainov, D.Ya. and Chernienko, V.A. Integral Estimates of Solutions to Nonlinear Systems and Their Applications. Nonlinear Dynamics and Systems Theory, 16 (1) (2016) 1-11.

[3] Pecora, L, and Carroll, T. Synchronization in chaotic systems, Physics Review Letter 64 (1990) 821-824.

[4] Vincent, U.E., Saseyi, A. and McClintock, P. V. E. Multi-switching combination synchronization of chaotic systems, Nonlinear Dynamics 80 (1) (2015) 845-854.

[5] Adel, Q. Chaos Synchronization Approach Based on New Criterion of Stability, Nonlinear Dynamics and Sys- tems Theory, 14 (4) (2014) 395-401.

[6] Meng, Z., Wang, X., Gong, X., Wei, G. and Lai, C. Complete synchronization and generalized synchronization of one-way coupled time-delay systems, Physical Review E 68 (2003) 036208(1-5).

[7] Adel, Q. A New Synchronization Scheme for General 3D Quadratic Chaotic Systems in Discrete-Time, Nonlin- ear Dynamics and Systems Theory, 15 (2) (2015) 163-170

[8] Rosenblum, M.G., Pikovsky, A.S. and Kurths, J. Phase synchronization of chaotic oscillators," Physical Review Letters 76 (11) (1996) 1804-1807.

[9] Rosenblum, M.G., Pikovsky, A.S. and Kurths, J. From phase to lag synchronization in coupled chaotic oscillators,, Physical Review Letters 78 (22) (1997) 4193-4196.

[10] Rulkov, N.F., Sushchik, M.M., Tsimring, S. and Abarbanel, H.D.I. Generalized synchronization of chaos in directionally coupled chaotic systems, Physical Review E 51 (2) (1995) 980-994.
[11]Roy, P.K., Hens, C., Grosu, I. and Dana, S.K. Engineering generalized synchronization in chaotic oscillators, Chaos 21 (2011) 0131061(1-7).

[12] Wang, X., Ying, Z. and Hu, G. Controlling hamiltonian systems by using measure synchronization, Physics Letters A 298(5-6) (2002) 383-387.

[13] Vincent, U.E., Njah, A.N. and Akinlade, O. Measure synchronization in a coupled hamiltonian system associated with nonlinear schrdinger equation,, Modern Physics Letters B 19 (15) (2005) 737-742.

[14] Wang, X., Zhan, M., Lai, C.H. and Gang, H. Measure synchronization in coupled 4 hamiltonian systems, Phys- ical Review Letters E 67 (6) (2003) 0662151(16).

[15] Hu, M.F. and Xu, Z.Y. Adaptive projective synchronization of unified chaotic systems and its application to secure communication, Chinese Physics 16 (11) (2007) 3231-3237.

[16]Li, Z.G. and Xu, D.L. Stability criterion for projective synchronization in three-dimensional chaotic systems, Physics Letter A 282 (3) (2001) 175-179.

[17] Mainieri, R. and Rehacek, J. Projective synchronization in three-dimensional chaotic systems, Physical Review Letter A 82 (15) (1999) 3042-3045.

[18] Kostur, M., Hnggi, T.P. and Meteos, J.L. Anticipated synchronization in coupled inertia ratchets with timedelayed feedback: a numerical study, Physical Review E 72 (3) (2005) 036210(1-15).

[19] Voss, H.U. Anticipated synchronization, Physical Review E 61 (5A) (2000) 5115-5119.

[20]Femat, R. and Sols-Perales, G. Synchronization of chaotic systems with different order, Physical Review E 65 (3) (2002) 0362261(1-4).

[21] Vincent, U. and Guo, R. Finite-time synchronization for a class of chaotic and hyperchaotic systems via adaptive feedback controller, Physics Letters A 375 (24) (2011) $2322-2326$.

[22] Kareem, S.O., Ojo, K.S. and Njah, A.N. Function projective synchronization of identical and nonidentical modified finance and Shimizu-Morioka systems, Pramana Journal of Physics 79 (1) (2012) 7179.

[23] Ucar, A., Lonngren, K.E. and Bai, E.W. Multiswitching synchronization of chaotic systems with active con- trollers, Chaos, Solitons and Fractals 38 (1) (2008) 254-262.

[24]Wang, X.Y. and Sun, P. Multi-switching synchronization of chaotic system with adaptive controllers and un- known parameters, Nonlinear Dynamics 63 (2011) 599-609.

[25] Li, H.M. and Li, C.L. Switched generalized function projective synchronization of two identical/different hyper- chaotic systems with uncertain parameters, Physica Scripta. 86 (4) (2012) 1-8.

[26] Yu, F., Wang, C., Wan, Q. and Hu, Y. Complete switched modified function projective synchronization of a five-term chaotic system with uncertain parameters and disturbances, Pramana 80 (2) (2013) 223-235.

[27]Zhou, X., Xiong, X. and Cai, L. Adaptive switched generalized function projective synchronization between two hyperchaotic systems with unknown parameters, Entropy 16 (2014) 377-388.

[28] Radwan, A., Moaddy, K., Salama, K., Momani, I. and 


\section{International Journal of Science and Research (IJSR) \\ ISSN (Online): 2319-7064 \\ Index Copernicus Value (2013): 6.14 | Impact Factor (2015): 6.391}

Hashim, S. Control and switching synchronization of fractional order chaotic systems using active control technique, Journal of Advanced Research 5 (2014) 125-132.

[29] Ajayi, A.A., Ojo, K.S., Vincent, U.E. and Njah, A.N. Multiswitching synchronization of a driven hyperchaotic circuit using active backstepping, Journal of Nonlinear Dynamics 2014 (2014) 918586(1-10).

[30] Yang, Q. and Chen, C. A 5D hyperchaotic system with three Lyapunov exponent coined, International Journal of Bifurcation and Chaos 23 (6) (2013) 1350109(1-24).

[31] Yang, Q. and Chen, C. A chaotic system with one saddle and two stable node-foci, International Journal of Bifurcation and Chaos 18 (2008) 1393-1414.

[32] Barboza, B. and Chen, C. On the global boundedness of the chen system, International Journal of Bifurcation and Chaos 21 (2011) 3373-3385.

[33] Dias, F. S. and Mello, L. F. and Zhang, J. G. Nonlinear analysis in a lorenz-likesystem, Nonlinear Analysis: Real World Application 11 (2009) 3491-3500.

[34]Luo, Q. and Liao, X. and Zeng, Z. G. Sufficient and necessary conditions for lyapunov stability of lorenz system and their application, Sci. China Ser.F. Inf.Sc 53 (2010) 1574-1583.

[35]Zeng, C. and Yang, Q. and Wang, J. Chaos and mixed
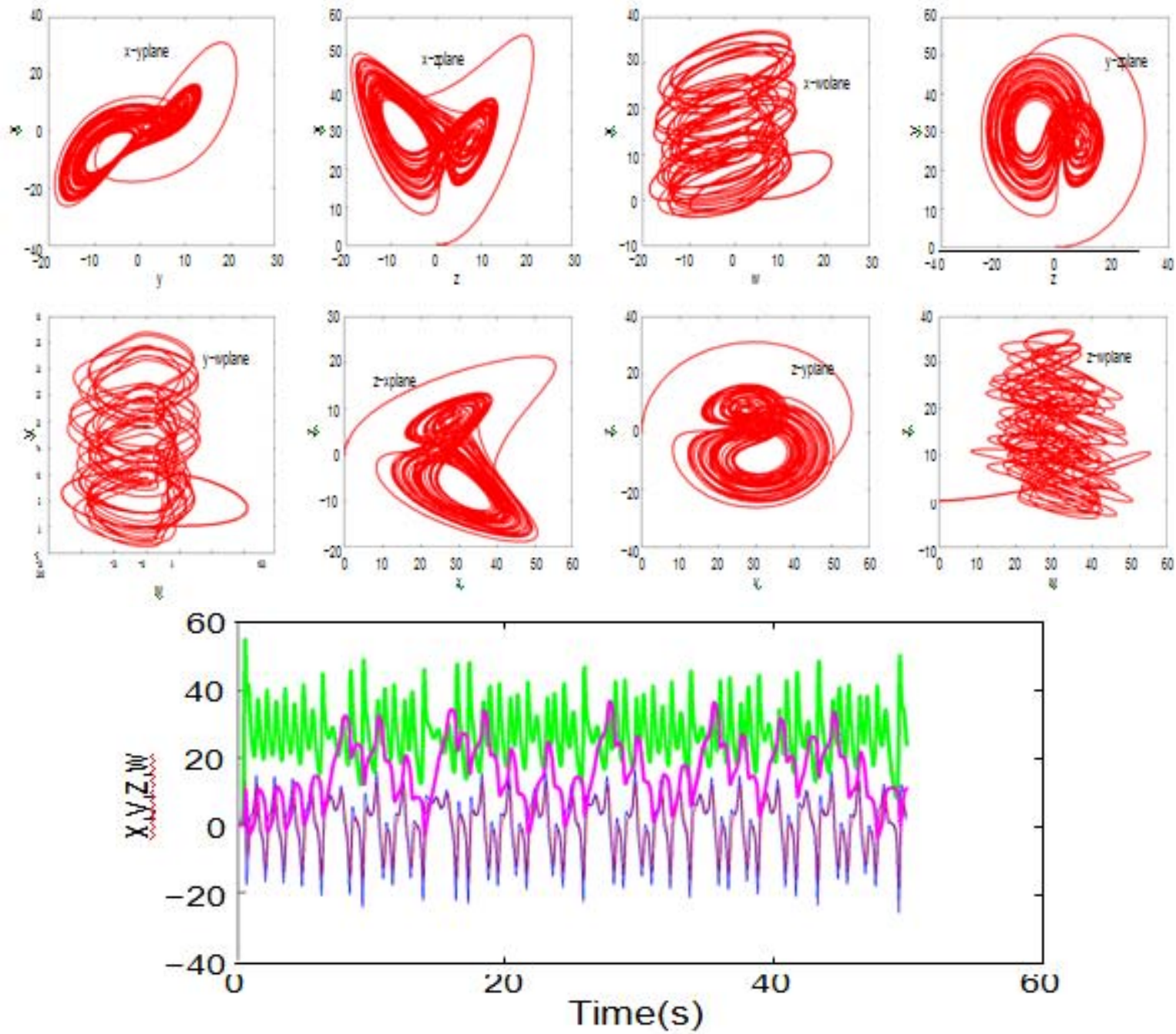

Figure 1: Lorenz system. The upper part of the figure shows some of attractors of the system for planes $x-y, x-z, x-w$, $y-z, y-w, z-x, z-y$ and $z^{-}-w$ where synchronization could take place, while the lower part shows the time series of the whole system at $\mathrm{a}_{1}=10, \mathrm{~b}_{1}=8 / 3, \mathrm{c}_{1}=28, \mathrm{~d}_{1}=0.1$,

are shown respectively

Volume 5 Issue 7, July 2016 www.ijsr.net

Licensed Under Creative Commons Attribution CC BY 


\section{International Journal of Science and Research (IJSR) \\ ISSN (Online): 2319-7064}

Index Copernicus Value (2013): 6.14 | Impact Factor (2015): 6.391
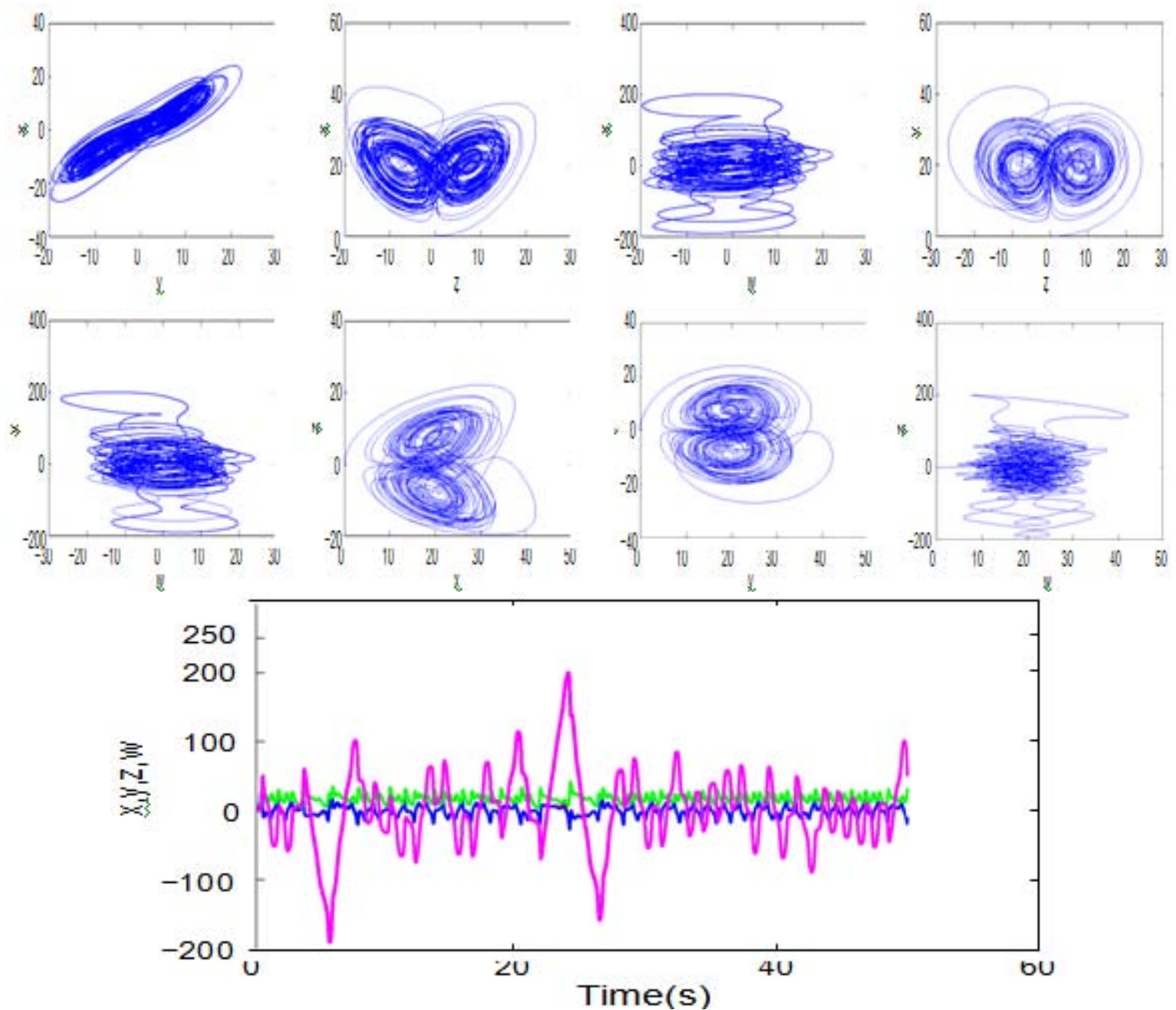

Figure 2: Chen system. The upper part of the figure shows some of attractors of the system for planes $x-y, x-z, x-w, y-z, y-$ $\mathrm{w}, \mathrm{z}-\mathrm{x}, \mathrm{z}-\mathrm{y}$ and $\mathrm{z}-\mathrm{w}$, while the lower part shows the time series of the system for the Chen system at $\mathrm{a}_{2}=35, \mathrm{~b}_{2}=3, \mathrm{c}_{2}=12$, $\mathrm{d}_{2}=7, \mathrm{e}=0.5$
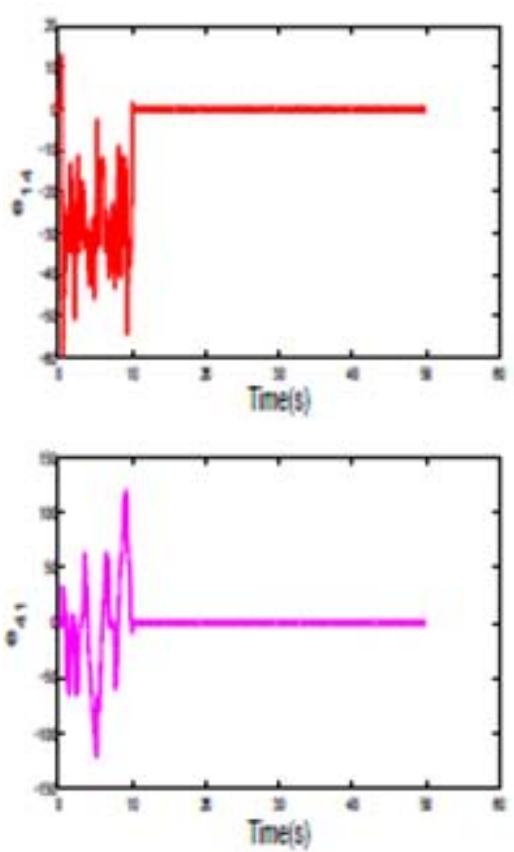
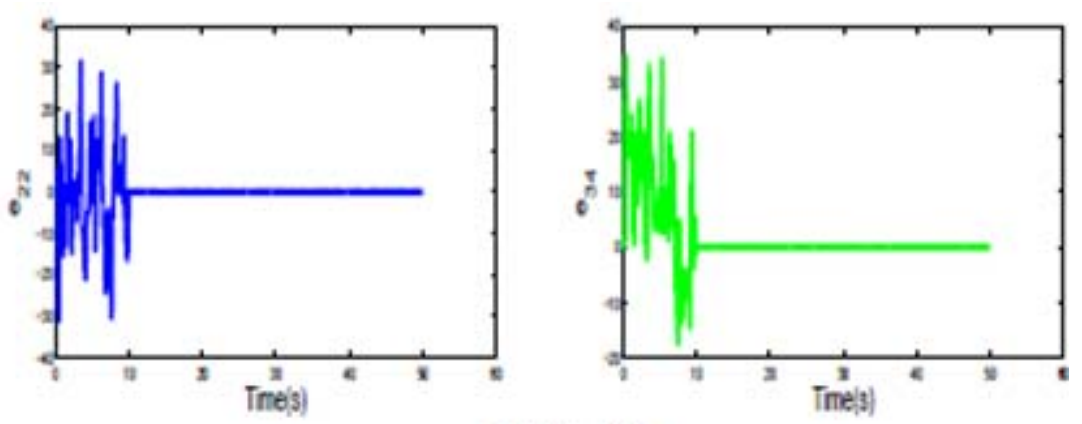

Contined case 1

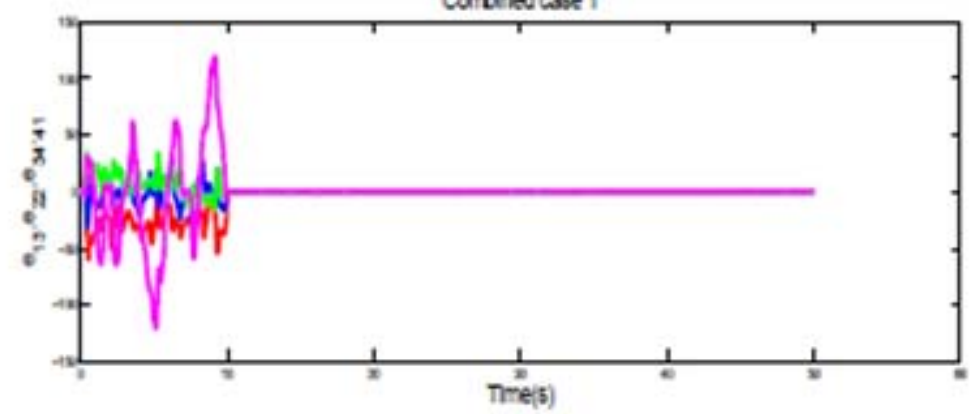

Figure 3: Synchronized state $\mathrm{e}_{13}, \mathrm{e}_{22}, \mathrm{e}_{34}, \mathrm{e}_{41}$ as shown in (a), (b), (c) and (d) respectively while (e) shows the combined synchronized state of case 1 of non-identical Lorenz (drive) and Chen (response) systems when $\mathrm{a}_{1}=10, \mathrm{~b}_{1}=8 / 3, \mathrm{c}_{1}=28$, $\mathrm{d}_{1}=2.25$, with initial condition values $\mathrm{x}_{1}=0.1, \mathrm{y}_{1}=0.1, \mathrm{z}_{1}=0.1, \mathrm{w}_{1}=0.1$, the hyperchaotic Chen system (response), parameters selected remain constant at $\mathrm{a}_{2}=35, \mathrm{~b}_{2}=3, \mathrm{c}_{2}=12, \mathrm{~d}_{2}=7, \mathrm{e}=0.5$ and variable parameters chosen as $\mathrm{x}_{2}=0.5, \mathrm{y}_{2}=$

Volume 5 Issue 7, July 2016 www.ijsr.net

Licensed Under Creative Commons Attribution CC BY 

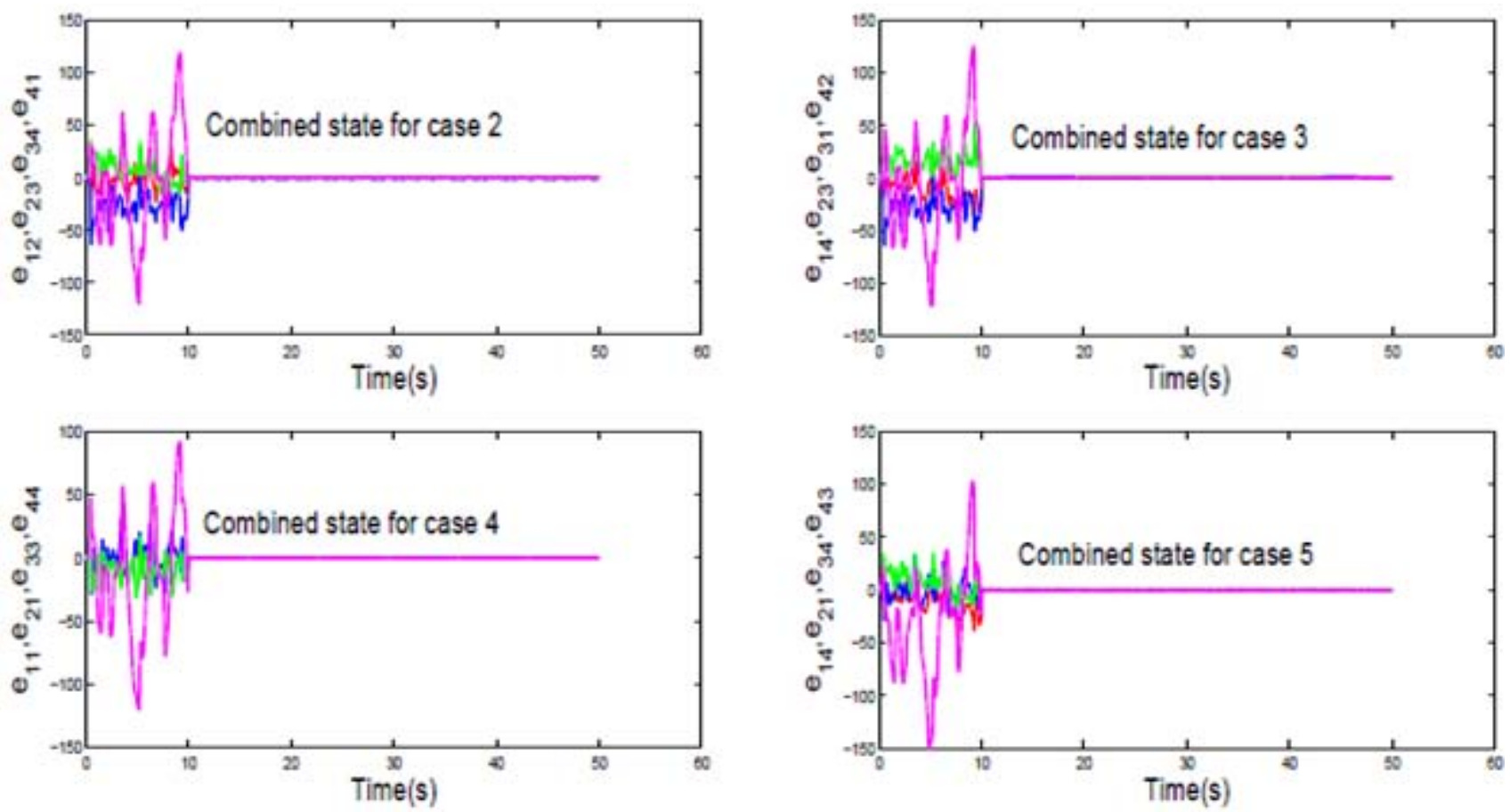

Figure 4: Combined Synchronized state for cases 2,3,4 and 4 non-identical Lorenz (drive) and Chen (re-sponse) systems when $\mathrm{a}_{1}=10, \mathrm{~b}_{1}=8 / 3, \mathrm{c}_{1}=28, \mathrm{~d}_{1}=2.25$, with initial condition values $\mathrm{x}_{1}=0.1, \mathrm{y}_{1}=0.1, \mathrm{z}_{1}=0.1, \mathrm{w}_{1}=0.1$, the hyperchaotic Chen system (response), parameters selected remain constant at $\mathrm{a}_{2}=35, \mathrm{~b}_{2}=3, \mathrm{c}_{2}=12, \mathrm{~d}_{2}=7, \mathrm{e}=0.5$ and variable parameters chosen as $\mathrm{x}_{2}=0.5, \mathrm{y}_{2}=0.01, \mathrm{z}_{2}=0.8, \mathrm{w}_{2}=0.5$. The step size was maintained at $\mathrm{H}=0.005$ and $\mathrm{t} \geq 10 \mathrm{~s}$ 